\title{
Greek student's politicization: empirical research in schools of central Macedonia in Greece
}

\section{Anthony D. Papaoikonomou}

Post-doc researcher in school of politics of Aristotle University of Thessaloniki

\begin{abstract}
This paper presents a research that was carried out in schools of central Macedonia in Greece about the degree of students' politicization. The concept of politicization was delineated using five different variables that describe students' way of thinking about different aspects of their reality. The findings show that peer group was considered to be the most important socializing factor which has a determining role in the political socialization of students. The degree of politicization is equivalent with the attendance in bars and the frequent watching of political programs on television.
\end{abstract}

Submitted

26.06.2016

Accepted

30.04.2017

Keywords:

student, school,

politicization

\section{Suggested Citation:}

Papaoikonomou, A.D. (2017). Greek student's politicization: empirical research in schools of central Macedonia in Greece, International Journal of Academic Research in Education, 3(1), 07-20. DOI: 10.17985/ijare.398830

\footnotetext{
${ }^{1}$ Lecturer, University of Macedonia papaoiko@sch.gr
} 


\section{Introducing the concept of political socialization}

The political socialization (politicization) attracted the attention of social scientists because it was considered that it could explain the function of political institutions and procedures. Many definitions have been proposed: According to Greenstein (1968) and Calavita (2005) the term refers to a) the acquisition of norms that dominate in the society and b) to the political learning of any kind. Having such a large width of criteria, it is very hard to be given a definition which would be able to include everything. Greenstein (1970: 54) distinguishes between specific and general definitions of political socialization. According to him, the definition that best describes political socialization is as follows: Political socialization is "...the intentional implantation of the political information, the values and the practices by institutions which are assigned for this responsibility; also, political socialization refers to the political learning, formal and informal, intentional and not, in every stage of life, including not only what has been defined as political learning but also of politically relevant characteristics of personality".

Rush \& Althoff (1971: 13-14) define political socialization as "the procedure with which the individual familiarizes himself/ herself with the political system and determines in this way his convictions about politics and political phenomena. It includes the examination of social, economic and cultural environment of a society and its impact on the individual and his/her political attitudes and values. The political socialization is the most important connection between the social and political systems, but it can be quite different from the one system to the other".

According to Sigel (1989: xii), "the political socialization refers to the procedure with which the individuals learn to adopt the norms, the values, the attitudes and the behaviors that are largely accepted from the existing systems. This kind of learning however, includes much more than the acquisition of the knowledge of political norms of the society as well as and much more than the credible application of these political actions; it suggests also that the individual will be familiar with these norms and behaviors - will internalize them - in a way that they look to him/her just and moral". Patrick (1977: 92) states that

political socialization deals with experiences that aim at the formation of human actions supporting social and cultural order.

All the previous definitions have two common characteristics: at first, they have defined political socialization as the procedure with which norms, values and behaviors are learnt by the individuals; Easton \& Dennis refer to "the developmental procedures with which individuals socialized politically" (1980: 7) whereas Dawsom \& Prewitt refer to "the developmental procedure with which the citizen matures politically" (1969: 71). Similarly, Rush \& Althoff (1971: 3) consider political socialization as "the procedure which results the elaboration of the personality of the individual so as to obtain all the political oriented experiences that he ought to. These experiences are not only political but they are considered relevant because they form his/her political behavior". Scholars however, question the way with which young people obtain these values; also, they put into consideration the assumption that these values are real for the youngsters. What is generally known, is the fact that in a specific time an individual will join a given political ideology and will accept its values and norms. This consideration of political 
socialization overlooks the idiosyncratic and personal development of the young individual (Dahlgren, 2009). Therefore, there is the need for knowledge of the idiosyncrasy of the individual; the full frame of behavior for the study of political socialization is not necessary the study of conformation and of maintenance of the status quo (Conover, 1991 C Colby, Beaumont, Ehrlich, \& Corngold, 2007).

The second characteristic of the definitions of political socialization is the emphasis on its instrumental character aiming at the formation of a conventional frame in which new man will be part of, given the fact that the existing status quo has to be reproduced and at the same time underestimates the abilities of the youngsters to renovate and to modify political learning. Rush \& Althoff (1971: 30) state that "political socialization is characterized by a complex network of knowledge, values and attitudes which are conveyed among the individuals and the groups within a given political system, resulting in the contribution of a set of experiences that are interweaved around the personality of an individual aiming at the formation of political behavior". The scholars that give emphasis on this point use terms like “cultural communication”, “adoption of cultural norms” etc. Langton (1973: 4) poses it differently: "The political socialization in its wider conception refers to the way with which society transmits its political culture from one generation to the other".

The procedure of socialization influences every kind of social group and is connected with every type of social relation. It is considered by the scholars as one of the most important processes of systemic survival. As Almond puts it (1970: 27): “All the political systems tend to perpetuate their culture and their structures as time goes by and they succeed in this task through socialization procedure by the primordial and the secondary institutions through which new man is led to maturation".

It cannot be stated that there is a unique theory of political socialization, even though that there are generally three approaches: the first and maybe the dominating one comes from the assumption that the attitudes are learnt in a young age and are especially resistant; they are considered also determining factors of prediction of political stances in the adult life of the individual (Dawson \& Prewitt, 1969. Easton \& Dennis, 1969 - Gimpel, Lay, \& Schuknecht, 2003). This approach has an important influence on the political convictions that are obtained in childhood and in the structure of personality which is created this period and which, even though it is not visible, determines permanent orientations in politics and in the choices of the individual when he/ she comes to adolescence.

In the other side of theoretical spectrum, it is assumed that the political orientation of the individual can be subject to many differentiations and modifications during his/ her life, provided that specific motives are given (Hahn, 1998 Hart \& Fegley, 1995). This approach puts forward the point of view that during adult life the individual contacts with a multitude of new facts and events, new experiences and responsibilities, as well as with changes of its social position. Changes are also observed in his/ her biological condition. All the above have a determining impact on the socializing process. Some aspects of socialization can be based on values and attitudes that have been obtained in childhood, in other case some other aspects are created de novo the moments that no socialization process takes place.

The third theoretical approach stresses the importance of different generations on individual attitudes during adult life (Harwood \& Creighton, 1993· Inglehart, 1990). This approach attributes an important role on events that form the attitudes, considering that these events will be interpreted differently by the age groups which share common values and points of view in the framework of their 
educational infrastructure. The age in which this specific event took place plays also important role, as well as the reaction of peer groups in this event.

As a conclusion, political socialization describes the procedure through which the individual, obtaining his/ her experiences from the childhood until the adult life, learns to develop political orientations, to form attitudes and to express moods about the political phenomena and procedures. The main purpose of political socialization is the acquisition on behalf of the individual of the reactions, the knowledge and the evaluation of the political phenomenon. It is the joint between the individual and the political system, which can contribute to a political culture sometimes towards the direction of political stability and sometimes towards the evolution of the existing culture.

\section{Aim of the research}

The theoretical frame of political socialization that was examined above was used to examine the degree of politicization of Greek adolescent students in relation with their everyday habits. Student politicization was delineated using five different variables:

- The first variable dealt with the equal treatment of all humans and the problems that could arise because of the denial of some people to apply it;

- the second dealt with the student participation in political activities;

- the third dealt with students' opinion about the responsibility they have to take action and improve the society they live in;

- the fourth with the connection between the good citizen and the undertake of responsibilities and,

- the last with his/her point of view about his/her ability to understand significant political issues that faces his/her country.

These variables are connected with familiar models of analyzing politicization that were used in previous researches (Mussen \& Warren, 1970: 277. Milner, 2002). Also, influences were examined between these variables and independent factors as the gender of the students, their performance in the previous class, their age etc.

\section{Methodology of research}

Despite its limitations, for the examination of the research problem, the survey was considered to be the most appropriate method, as it ensured the participation of a large number of pupils. The survey was addressed to pupils from secondary schools of Central Macedonia in Greece, in particular the regions of Kilkis and Thessaloniki, so as to include the views of students from urban, semi-urban and rural areas.

The questionnaire of this study was based on two previous studies that had been conducted for similar reasons. The first was the research conducted by Kelpanidis (2012) and it concerned the examining of pupils' points of view on occupations (sits-in) of schools during the academic year. The second was a research conducted by Stavrakakis and Demertzis (2008), and it examined the young people's attitudes on different issues of their daily life. Initially, a pretest research was conducted in a lyceum class so as to 
ascertain the pupils' attitude towards the questionnaire and to calculate the time needed to answer the questions. In general terms, the results showed a good reception of the research instrument, while the time did not exceed 25 minutes. Once the research was approved by the Institute of Educational Policy and instructions were given, letters were sent to the students' parents in order for them to consent to the pupils' participation. It has to be noted that all parents approved the students' participation without any objections. Of the 1,100 questionnaires that were distributed to pupils, 960 were returned. The data presented below, are from the final questionnaire.

Stratified sampling was used, in order to collect data from different school levels. More analytically, six schools from central Macedonia were involved: a general lyceum and a gymnasium of Thessaloniki (which is in an urban area), a vocational school from the prefecture of Kilkis, two general lyceums and a gymnasium from the prefecture of Kilkis (a semi-urban area, since the town's population is over 10,000 inhabitants) and, finally, a lyceum and a gymnasium from villages with less than 2000 inhabitants (rural areas). The precise number of pupils regarding the area where they live, their gender, the ages of the pupils, the types of school and the class they attend sre presented in the following table (table 1):

\section{Table 1}

Descriptive data

\begin{tabular}{|c|c|c|}
\hline Area & Frequency & Percentage \\
\hline Urban & 236 & 24,6 \\
\hline Semi-urban & 509 & 53,0 \\
\hline Rural & 215 & 22,4 \\
\hline Total & 960 & 100,0 \\
\hline \multicolumn{3}{|c|}{ Gender } \\
\hline Boys & 525 & 54.7 \\
\hline Girls & 435 & 45.3 \\
\hline Total & 960 & 100.0 \\
\hline \multicolumn{3}{|c|}{ Ages of the pupils } \\
\hline 50 to 24 years old & 13 & 1,4 \\
\hline 23 to 17 years old & 258 & 26,9 \\
\hline 16 to 14 years old & 430 & 44,8 \\
\hline 13 and below & 132 & 13,8 \\
\hline Total & 833 & 86,8 \\
\hline Missing & 127 & 13,2 \\
\hline Total & 960 & 100,0 \\
\hline \multicolumn{3}{|c|}{ Types of school } \\
\hline Lyceum & 416 & 43,5 \\
\hline Gymnasium & 283 & 29,6 \\
\hline Vocational School & 257 & 26,9 \\
\hline Total & 956 & 100,0 \\
\hline Missing & 9 & 4 \\
\hline
\end{tabular}




\begin{tabular}{|l|c|c|}
\hline \multicolumn{1}{|c|}{ Area } & Frequency & Percentage \\
\hline Urban & 236 & 24,6 \\
\hline Semi-urban Class & 509 & 22,4 \\
\hline Rural & 215 & \\
\hline Total & 960 & 23,1 \\
\hline \multicolumn{1}{|c|}{ A Lyceum } & 217 & 15,7 \\
\hline B Lyceum & 147 & 31,1 \\
\hline C Lyceum & 292 & 10,2 \\
\hline A Gymnasium & 96 & 5,3 \\
\hline B Gymnasium & 50 & 14,6 \\
\hline C Gymnasium & 137 & 100,0 \\
\hline Total & 939 & \\
\hline Missing & 21 & \\
\hline Total & 960 & \\
\hline
\end{tabular}

As far as the pupils' ages were concerned, great variance was observed owing to the fact that only older pupils from the vocational school participated in the study. Also, due to the fact that in the particular area there is not a Second Chance School, many adults choose the vocational school in order to complete their secondary education.

Each pupil's performance - as depicted in the final grade - will be an important independent variable for further analysis. The following chart shows that the average grade of 740 pupils is 16.09 and its standard deviation is 2,351. It has to be noted that 220 pupils did not want to answer the questionnaire, claiming that this information is personal data and, as such, this information is irrelevant to the purpose of this research.

Graph 1

Pupils' grade

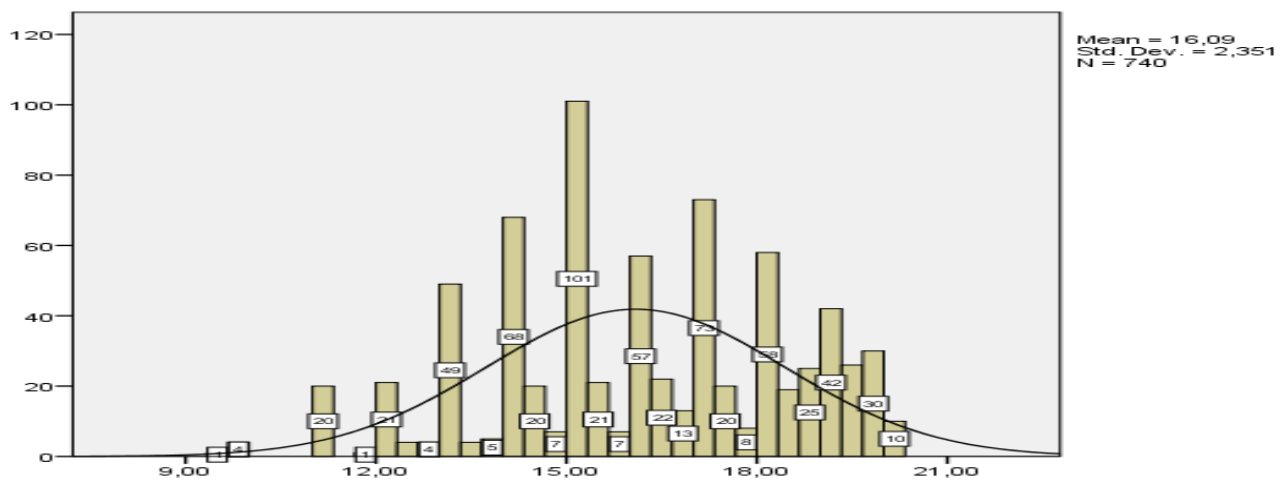


Next, some extra demographic data will be presented, which are considered as crucial factors in political socialization. The parents' profession was examined, as well as their educational level. Mother's and father's educational status were examined separately. Table 2 presents the frequencies of each case:

Table 2

Parents’ professional position

\begin{tabular}{|c|c|c|c|c|}
\hline & \multicolumn{2}{|c|}{ Father } & \multicolumn{2}{|c|}{ Mother } \\
\hline & $\begin{array}{c}\text { Frequenc } \\
y\end{array}$ & $\begin{array}{c}\text { Percentag } \\
\text { e }\end{array}$ & $\begin{array}{c}\text { Frequenc } \\
y\end{array}$ & Percentage \\
\hline Self-employed & 187 & 19,5 & 129 & 13,4 \\
\hline Freelance & 125 & 13,0 & 71 & 7,4 \\
\hline Employer (employs up to 5 persons) & 67 & 7,0 & 50 & 5,2 \\
\hline $\begin{array}{l}\text { Employer (employs more than } 5 \\
\text { persons) }\end{array}$ & 42 & 4,4 & 20 & 2,1 \\
\hline Civil servant (lower position) & 15 & 1,6 & 36 & 3,8 \\
\hline Private employee (lower position) & 40 & 4,2 & 59 & 6,1 \\
\hline Civil servant (medium position) & 114 & 11,9 & 122 & 12,7 \\
\hline Private employee (medium position) & 109 & 11,4 & 104 & 10,8 \\
\hline Private employee (senior position) & 47 & 4,9 & 36 & 3,8 \\
\hline Civil servant (senior position) & 54 & 5,6 & 29 & 3 \\
\hline Missing & 160 & 16,7 & 304 & 31,7 \\
\hline Total & 960 & 100,0 & 960 & 100,0 \\
\hline
\end{tabular}

As far as the value 'missing cases' is concerned, this refers to the cases where either the father or the mother does not work - willingly or not. The percentage of unemployed mothers is $31.7 \%$ and of unemployed fathers is $16.7 \%$. Regarding their educational level, the majority of both parents are higher secondary education (lyceum) graduates while also a large percentage of them are holders of university and technological educational institute degrees. Educational level frequencies are presented in the following table (table 3): 
Table 3

Parents' educational level.

\begin{tabular}{|lcc|c|c|}
\hline & \multicolumn{2}{|c|}{ Father } & \multicolumn{2}{c|}{ Mother } \\
\hline & Frequency & Percentage & Frequency & Percentage \\
\hline Up to primary school & 112 & 13,2 & 40 & 4,7 \\
certificate & & & & \\
Up to gymnasium & 133 & 15,7 & 137 & 16,2 \\
certificate & & & & \\
Up to lyceum certificate & 288 & 34,0 & 322 & 38,2 \\
Technological Institute & 196 & 23,2 & 174 & 20,6 \\
degree & & & & \\
University degree & 91 & 10,8 & 132 & 15,6 \\
Master's & 13 & 1,5 & 24 & 2,8 \\
PhD & 13 & 1,5 & 15 & 1,8 \\
Total & 846 & 100,0 & 844 & 100,0 \\
Missing & 114 & & 116 & \\
Total & 960 & & 960 & \\
\hline
\end{tabular}

\section{Results}

At first, pupils' answers in each variable are presented and then these answers will be correlated with the independent variables in order to put forward the crucial factors that influence pupils. Moreover, they will be correlated with pupils' daily activities in order to emerge the socializing factors that that have an impact on their behavior. Also, a cluster analysis was used and it showed that the dependent variables explained can be integrated into one hypervariable which will be called from now on politicization degree. Reliability analysis showed that reliability index Cronbach's alpha is 0.867. As far as the first variable is concerned two opposite conclusions are reached; whereas the majority (48.91\%) either agrees or fully agrees with the need egalitarianism to be achieved in a country, a significant percentage of $34.32 \%$ either disagrees or fully disagrees. In the same way, diverse are the answers for the second variable which deals with the students' adequacy to participate in political activities: high percentages $(43.6 \%)$ of the students asked do not believe that they are mature enough to participate in political activities including their participation to students' councils. 
Graph 2

If people were treated equally, we would have less problems in this country.

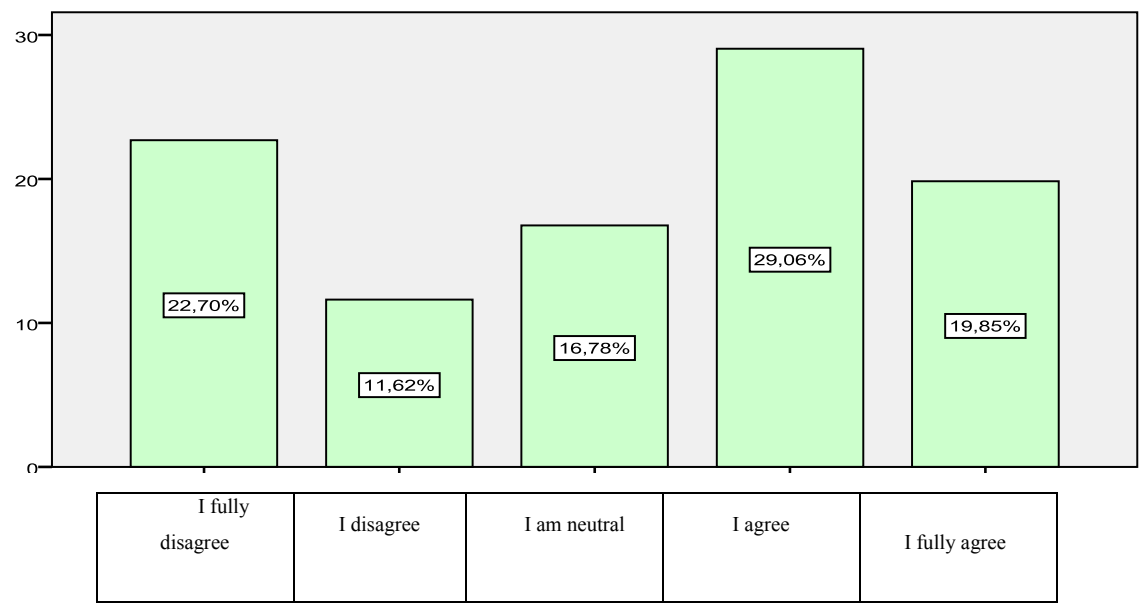

Graph 3

I consider myself capable of participating in political activities.

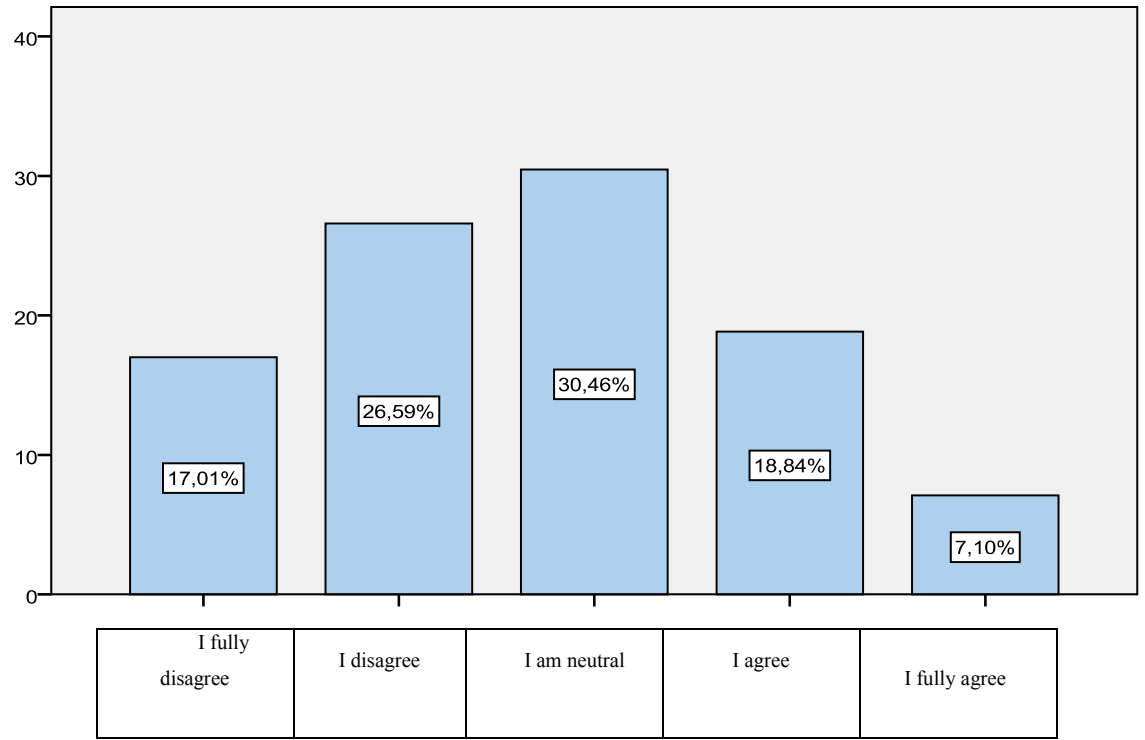

Fragmentized were students' points of view as far as the third variable is concerned, which regards the responsibility that every student should have for the improvement of the society. $20.81 \%$ fully disagrees whereas $18.63 \%$ simply disagrees with the undertake of responsibility on behalf of the students, while on the contrary $33.98 \%$ agrees or fully agrees with the need for the students to participate pursuing the amelioration of the society. A considerable significant percentage of the students responded is neutral. Relevant to the above variable is the following, which concerns with students' point of view regarding the definition of the good citizen. The smashing majority (63.33\%) agrees or fully agrees with the view that a good citizen is someone who undertakes responsibilities. This answer contradicts with the previous one, putting forward the paradox that even though they consider good citizen someone who undertakes responsibilities, the same students are not in a position to undertake these responsibilities so they do not consider themselves as good citizens. This paradox will be discussed later on and the probable causes will be examined. 
Finally, the presentation of the descriptive statistics is completed with students' view about the degree of comprehension about important political problems that their country faces: $43.35 \%$ consider that they have this ability, a fact that shows their readiness to undertake responsibilities $(\chi 2=143.957$, $\mathrm{df}=4, \mathrm{p}=0.000)$.

In this research, students were asked about their everyday activities aiming at examining their impact on students' politicizing degree. The questions concerned all the spectrum of free time activities i.e. the meetings with their friends, sports, personal computer theater, literature etc. In this paper, only statistical significant correlations will be presented due to economy and interest. ANOVA statistical method was used because of the variable type. The first statistical significant correlation that was recognized was the one between politicization degree and the meetings with friends $(\mathrm{F}=2.637, \mathrm{df}=4$, $\mathrm{p}=0.033$ ). The results and means controls showed that the students who meet everyday friends have higher politicization degree. Generally, the tendency that was delineated was that frequent meetings that have as a result more frequent conversations about different issues create more politically orientated individuals. In the following graph the vertical axis shows politicization degree whereas the horizontal the frequency of meetings with friends:

Graph 4.

Correlation between meeting with friends and degree of politicization

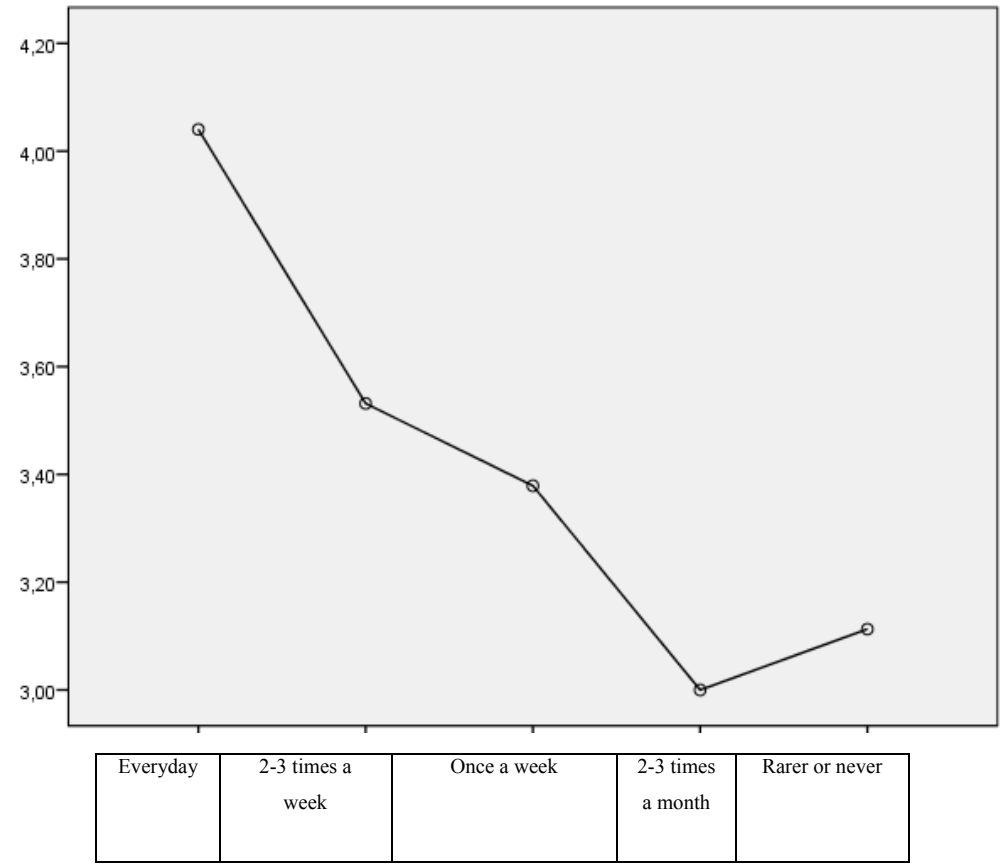

Interesting conclusions were reached by the corelation between watching sport programs on television and politicization degree $(\mathrm{F}=6.851, \mathrm{df}=4, \mathrm{p}=0.000)$. In this case everyday watching of these kind of tv programs is related in a statistical significant way with the high levels of political self-concept. The following graph shows the above conclusion: 


\section{Graph 5}

Correlation between watching sport programs on tv and degree of politicization

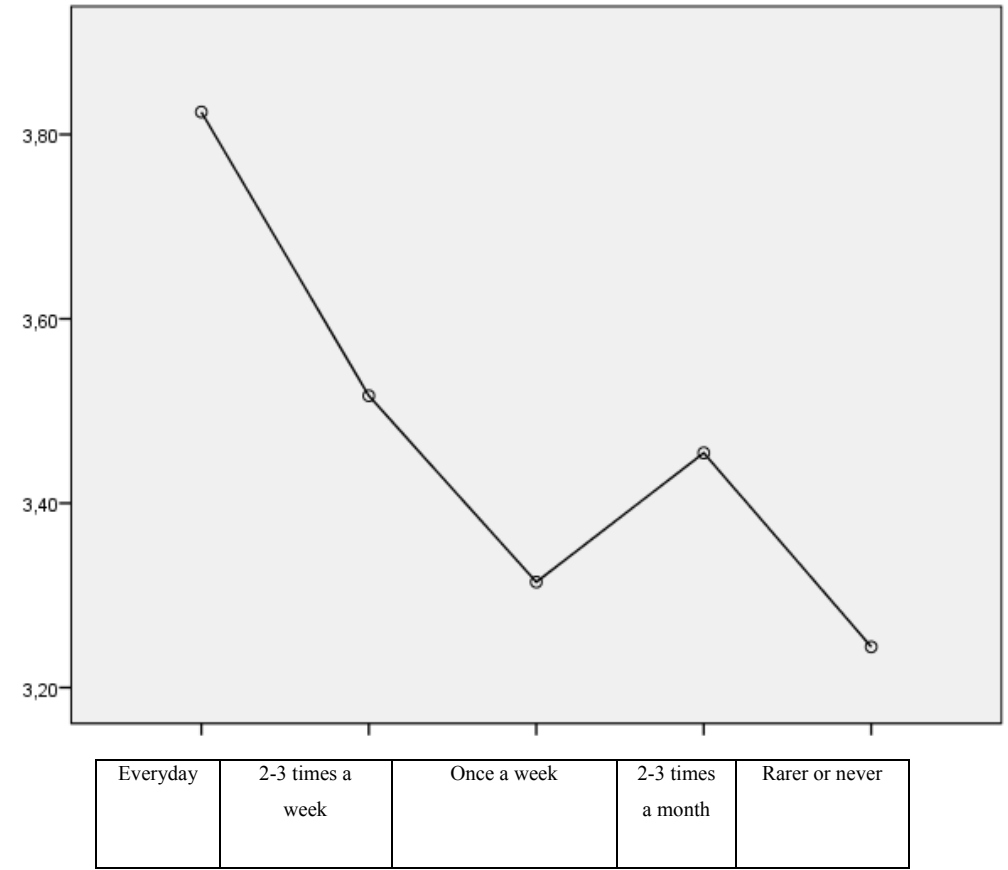

The same also applies with the habit of the students to frequent bars and generally entertainment youth centers. Analysis showed that there is a statistically significant correlation between students that go every day to entertainment centers (bars, clubs etc.) and politicization degree ( $\mathrm{F}=14.191, \mathrm{df}=4, \mathrm{p}=0.000)$ in relation to their fellow students that do not go regularly to these places. These findings prove that extroversion and the participation to social events with peer groups increase the probability to form a high level political behavior. The graph below shows the last finding:

Graph 6

Correlation between frequency to bars and degree of politicization

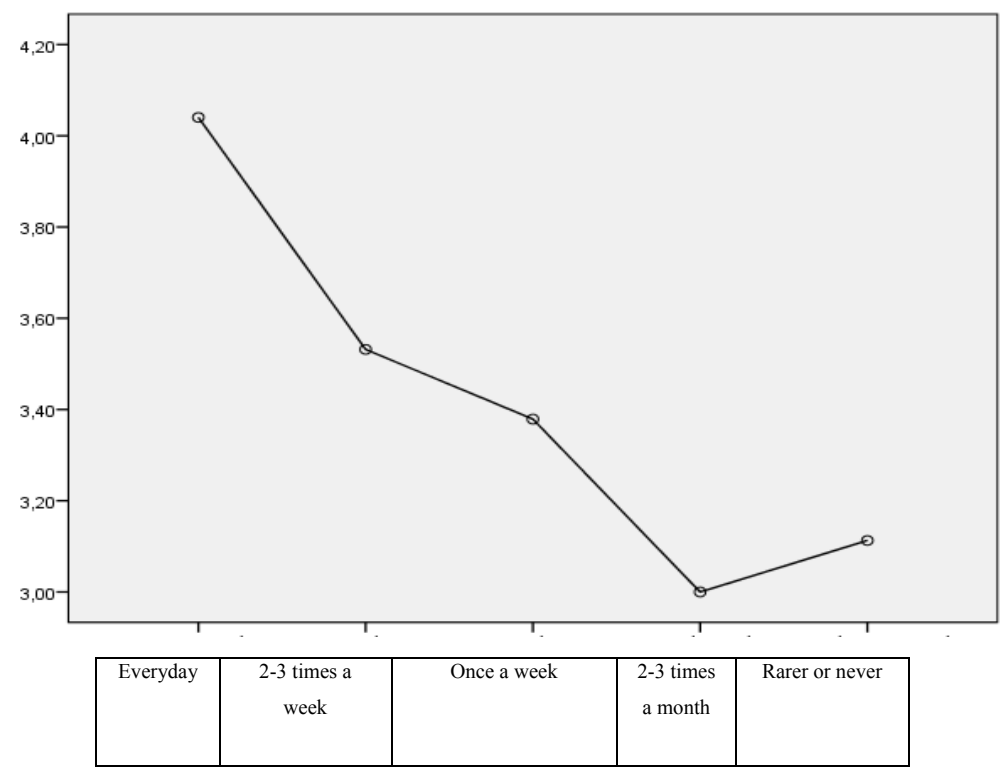


Other more "introverted" activities move to the same direction. Reading books which are related to the field of study that they want to follow correlate significantly with their political self-concept $(\mathrm{F}=3.491, \mathrm{df}=4, \mathrm{p}=0.013)$. The following graph shows that students that study books everyday have a higher degree of politicization $(\mathrm{F}=9.553, \mathrm{df}=4, \mathrm{p}=0.000)$.

Graph 7

Correlation between reading books and degree of politicization

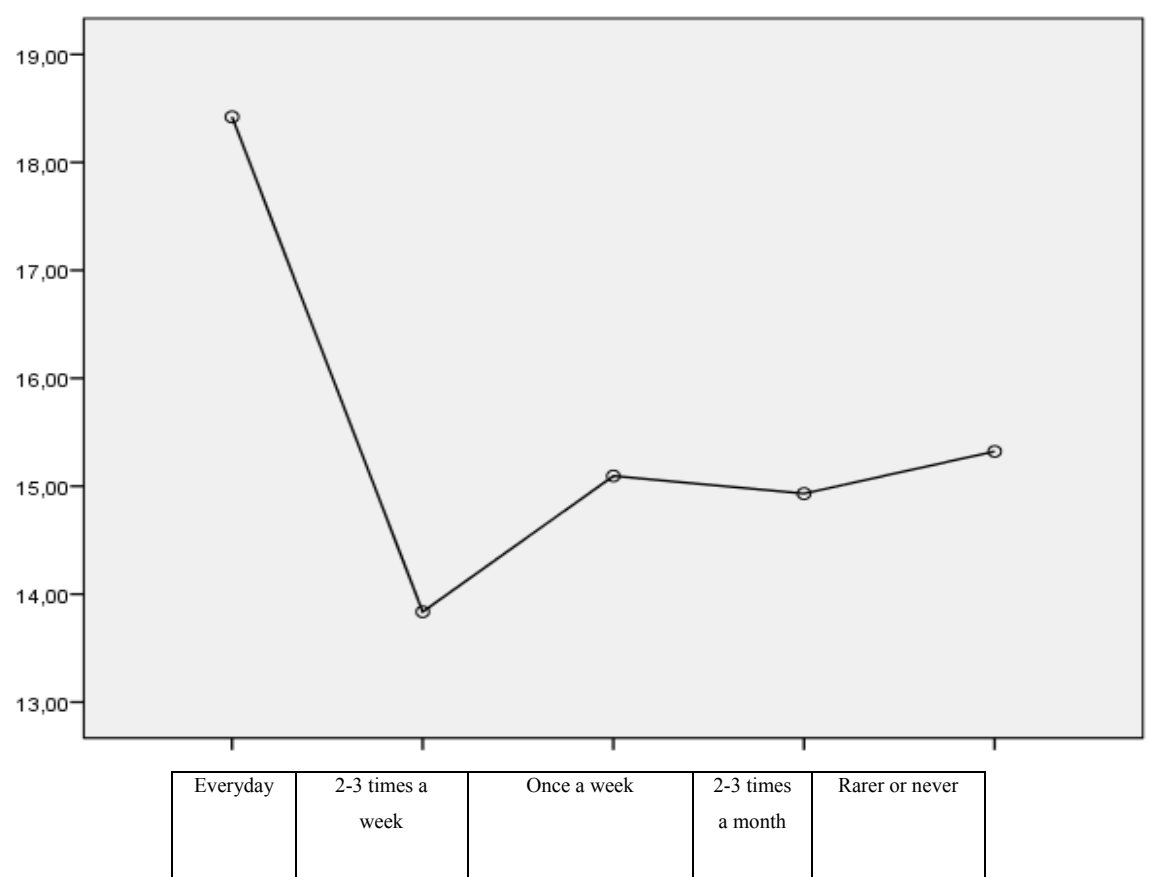

Finally, there have been correlations between students' performance in the last grade and their degree of politicization. Results showed that there is a statistical significant relation between these two variables which means that the higher the performance, the higher the degree of politicization (Pearson R: $0.271^{* *}$. Sig. (2-tailed): 0.000).

\section{Conclusions}

The main aim of this research was the measurement of the degree of politicization of the adolescent students of secondary education in Greece. The sample was consisted of students from schools of central Macedonia in Greece from urban, semi-urban and rural areas. For the analysis, variables were used which were united in one single hyper-variable (politicization degree). This hyper-variable acted as the dependent variable in the statistical analysis. Emphasis was given on the promotion of the role of everyday activities and of everyday habits and their impact on the degree of politicization. Generally, the analysis showed that peer groups present a positive impact on the levels of political self concept.

One of the most important socializing factors of the individuals is the degree of extroversion and the existence of peer groups. Through the promiscuity of the child with his/ her peer groups, he/ she learns to discard his selfishness so as to be a part of a group. In other words, it is a first stage where "I" transforms into "we". The significant need of the individual to be a part of a group and accepted is 
satisfied, boosting in this way his/ her sense of self-worthiness and self-esteem. In this research the important impact of the peer group in their politicization was proved. The findings also showed that frequent contacts, the common watching of sport television programs, the frequent hanging out with friends and the reading books which are related with their field of study have a positive impact on the degree of their political self-concept. Their peer groups function as models of alternative choices. Some researchers have moved on, so as to assume that the relationships with friends and peer groups are the most important relations in the life of an adolescent during his/her transition from childhood to adolescence and adult life (Youniss, 1980). Meeus \& Dekovic (1995) found that the identity, as it was measured by commitment in the field of relationships, school and work environment was influenced more by peer groups and that parent support had only a subordinate positive impact. Youniss hypothesis was altered by the research of other scholars who examined the combined influence of parents and peer groups. Bosma \& Kunnen (2001), claim that adolescents discuss with their peer groups political issues such as: what is the political situation in the country, which should be, who is the politician that articulates their interests etc. it is more probable to lean on peer groups models, when these models concern issues such as partisan identity, ideology, attitude towards the difference (Rathus, 2011). Meeus et al. (2002), found that this hypothesis had minimal empirical support. They discovered also that relations with parents and peer groups are connected with different areas of identity. Also, adolescents agree with their parents in serious issues such as moral principles and future educational and professional plans (Rathus, 2011). It seems that family and peer groups influence individual identity formation but in different aspects.

The research on politicization is a major issue because of phenomena such as political apathy that can lead to political "inertia". Systematic analysis of the impact of the socializing factors has to become a major pursue of social researches aiming at the designation of the causes that push future citizens to the formation of their political convictions.

\section{References}

Almond, G. (1970). Political development, Boston: Little Brown.

Bosma, A. \& Kunnen, S. (2001). Determinants and mechanisms in ego identity development: A review and synthesis. Developmental Review, 21, 39-66.

Calavita, M. (2005). Apprehending politics. Albany: State University of New York Press.

Colby, A., Beaumont, E., Ehrlich, T. \& Corngold, J. (2007). Educating for democracy: Preparing undergraduates for responsible political engagement, San Francisco: Jossey-Bass.

Conover, P. (1991). Political Socialization: Where's the Politics? In Political science: Looking to the future: Volume III, Political Behavior, edited by William Crotty, 125-152. Evanston, Ill.: Northwestern University Press.

Dahlgren, P. (2009). Media and political engagement: Citizens, communication and democracy, Cambridge: Cambridge University Press.

Dawson, R. E. \& Prewitt, K. (1969). Political socialization. Boston: Little, Brown and Company.

Demertzis, N. \& Stayrakakis, J. (2008). Youth: the imponderable factor, Athens, Polytropon (in Greek). 
Easton, D, \& Dennis, J. (1969). Children in the political system. New York: John Wiley \& Sons.

Easton, D. \& Dennis, J. (1980). Children in the political system: origins of political legitimacy. Chicago: University of Chicago Press.

Gimpel, J., Lay, J. C., \& Schuknecht, J. E. (2003). Cultivating democracy: Civic environments and political socialization in America. The Brookings Institution: Washington, DC.

Greenstein, F. (1968). Political socializations. In Sills, D. (ed.) International Encyclopedia of Social Sciences, New York: Macmillan and Free Press.

Hahn, C. L. (1998). Becoming political. Albany: State University of New York Press.

Hart, D. \& Fegley, S. (1995). Prosocial behavior and caring in adolescence: Relations to selfunderstanding and social judgment, Child Development, 66, 1347-1359.

Harwood, R. \& Creighton, J. (1993). College students talk politics, Dayton, OH: Kettering Foundation.

Inglehart, R. (199). Culture shift. Princeton, N.J.: Princeton University Press.

Langton, K. (1973). Political socialization, New York: Oxford University Press.

Meeus, W., \& Dekovic, M. (1995). Identity development, parental and peer support in adolescence: Results of a national Dutch survey. Adolescence, 30, 931-944.

Milner, H. (2002). Civic literacy: How informed citizens make democracy work. University Press of New England.

Mussen, P. \& Warren, A. (1970) Personality and political participation. In Sigel, R. (ed.) Learning about Politics: a reader in political socialization, New York, Random House, 277-293.

Patrick, J. (1977). Political Socialization and Political Education in Schools. In Renshon, S. (Ed.) Handbook of political socialization: Theory and research, New York, Free Pres.

Rathus, S. A. (2011). Childhood and adolescence: Voyages in development. Wadsworth: Cengage Learning.

Rush, M. \& Althoff, P. (1971). An introduction to political sociology. London: Nelson.

Sigel, R. (1989). (ed) Political learning in adulthood. Chicago: University of Chicago Press.

Youniss, J. (1980). Parents and peers in social development. Chicago: University of Chicago Press. 